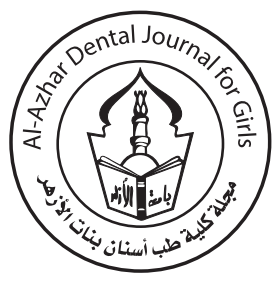

\title{
Effect of Two Denture Teeth Materials on Masticatory Efficiency, Wear, Bonding to Denture Base
}

\author{
Maha A. Ezzat ${ }^{1 *}$, Hala M. Gamal El-Din ${ }^{2}$, Shereen M. Kabeel ${ }^{3}$
}

Codex : 02/22.01

azhardentj@azhar.edu.eg

http://adjg.journals.ekb.eg

DOI: $10.21608 /$ adjg.2021.42852.1295

Restorative Dentistry

(Removable Prosthodontics, Fixed

Prosthodontics, Endodontics, Dental Biomaterials, Operative Dentistry)

\section{KEYWORDS}

Nano composite,

Acrylic teeth, Masticatory

efficiency, Wear, Bond strength

\begin{abstract}
Purpose: This study compared between nano composite denture teeth and IPN crosslinked acrylic teeth regarding masticatory efficiency and some mechanical properties (wear, micro tensile bonding strength to denture base). Material and methods: Ten completely edentulous patients with ages ranging from 55-60 years were selected. Each patient received two dentures made from heat-cured acrylic resin, One with IPN crosslinked acrylic teeth and the other with nano composite teeth. Masticatory efficiency was evaluated for each patient at the time of insertion of the dentures and one month later. Laboratory study: For testing wear, thirty specimens were constructed and divided into two groups. Fifteen IPN cross-linked acrylic teeth (Group I) and Fifteen nano composite denture teeth (Group II). For testing Micro tensile bonding strength, Twelve specimens were constructed of artificial teeth together with the heat-cured acrylic resin bases, These specimens were fixed to a micro- sawing machine and cut into one hundred and twenty micro beam samples which were then divided into two groups; sixty beams of IPN cross-linked acrylic teeth (Group I) and sixty beams of nano composite denture teeth (Group II). Results: The results revealed no statistical significant differences ( $\mathrm{p}$ $\leq 0.05$ ) as indicated by paired t-test between IPN cross-linked acrylic teeth and nano composite teeth in masticatory efficiency, wear, and micro tensile bonding strength to the denture base. Conclusions: In comparison to IPN cross-linked acrylic teeth, nano composite denture teeth showed non-significant difference regarding masticatory efficiency, wear resistance, and micro tensile bonding strength to the denture base.
\end{abstract}

* Paper extracted from Master thesis titled "Effect of Two Denture Teeth Materials on Masticatory Efficiency, Wear, Bonding to Denture Base."

1. Dentist at Ministry of Health

2. Professor of Removable Prosthodontic Department, Faculty of Dental Medicine for Girls, Al-Azhar University.

3. Assistant Professor of Removable Prosthodontic Department, Faculty of Dental Medicine for Girls, Al-Azhar University.

*Corresponding author email: mahaezzatahmed0@gmail.com 


\section{INTRODUCTION}

Conventional complete dentures are still the most widely used treatment for edentulous patients for medical and financial reasons, although rehabilitation with Osseointegrated implants has been increased over the last decades ${ }^{(1)}$.

Several problems with complete dentures wearing have been reported. One of the most frequent complains is that complete denture wearers have masticatory efficiency which is only $16 \%$ to $50 \%$ that of dentate patients. This low masticatory performance affects their food choices due to difficulty in consuming high-fibrous foods and hence affects their quality of life ${ }^{(2)}$.

Lack of sufficient wear resistance of denture teeth is a major problem in the prosthodontics practice as it results in loss of vertical dimension of occlusion, loss of masticatory performance, an improper occlusal relationship which may subsequently increase horizontal stresses and affect esthetics and function ${ }^{(3)}$.

It has been reported that denture teeth debonding from denture base is the cause of $22 \%$ to $30 \%$ of denture repairs ${ }^{(4)}$. Bond failure between denture teeth and denture base is either adhesive failure where there is no remnants of denture base material on the teeth ridge lap portion after fracture or cohesive failure where the fracture is within the denture base material or the tooth material ${ }^{(5)}$.

The most widely used denture teeth in denture fabrication are acrylic resin denture teeth due to their convenient handling, ease of contouring, high resilience, and bonding chemically to denture base; however, one of their major disadvantages is excessive wear with its unfavorable associated sequelae ${ }^{(6,7)}$.

Nano composite denture teeth were introduced to the market as a result of the developments in nanotechnology field. They are composed of urethane dimethyl methacrylate (UDMA) and PMMA composite matrix with silicon inorganic Nano fillers.
Nano composite teeth are characterized by having superior esthetics without affecting their mechanical properties ${ }^{(8)}$.

The objective of this study was to compare the masticatory efficiency, wear resistance, and bonding to denture base of IPN cross-linked acrylic teeth with the newly introduced nano composite teeth.

\section{MATERIAL AND METHODS}

\section{Clinical study}

Ten completely edentulous patients were chosen from the Removable Prosthodontics Department's outpatient Clinic of the Faculty of Dental Medicine, Al-Azhar University for Girls. Patients ages ranged from 55-60 years, free from any systemic diseases which might affect masticatory muscles. All patients had residual alveolar ridges with moderate height, width, free from any severe bony undercuts, and covered with healthy firm mucosa without inflammation signs, ulceration, or hyperplasia. Patients with Parafunctional habits as bruxism were excluded from the study. All patients accepted this dental treatment, the steps of this study were explained to them and they signed a written consent. Approval of REC (Research Ethics Committee) of the Faculty of Dental Medicine for Girls, AL- Azhar University was obtained. Patient history and clinical examination for medical, dental, extraoral, intraoral, laboratory investigation, and radiographic examination were then carried out for each patient.

Primary impressions were taken with irreversible hydrocolloid impression material (Alginate)with stock trays of suitable size, then a secondary impression was taken using Silicone impression material (poly-C-silicone impression material, thixoflex $\mathrm{M}$, medium, Zhermack, Italy) after border molding with (Putty-C-Silicone). Impressions were disinfected, boxed, and then poured using dental stone to produce master casts which were then used for the construction of permanent denture bases made 
of heat-cured acrylic resin with IPN Cross-Linked acrylic teeth and the master casts were duplicated for construction of heat- cured acrylic resin denture base with nano-composite artificial teeth.

Following the adjustment of the maxillary occlusion rim and the occlusal plane orientation, a maxillary face bow record was taken for mounting of the maxillary cast on a semi-adjustable articulator (Hanau model $\mathrm{H}$ articulator), then centric occlusion was recorded to mount the mandibular cast using the wax wafer technique. Setting up artificial teeth was made and to standardize the size and form of teeth, IPN Cross-linked and Nano-Composite teeth were obtained from the same company. Then waxing up of trial denture bases was completed. The denture has been tried in the patient's mouth to check denture extension, retention, centric occluding relation, esthetics, and phonetics.

Curing, deflasking, finishing, and polishing were performed. Finally, two sets of complete dentures with two heat-cured acrylic denture bases were obtained. One with IPN cross-linked acrylic teeth, the other with nano composite teeth.

\section{Evaluation of masticatory efficiency}

All patients received complete dentures with IPN cross-linked acrylic teeth and were asked to wear their dentures one week for adaptation, before measuring of the masticatory efficiency in which the Patients were instructed to chew standardized pieces of food: banana which represented soft food and carrot which represented hard food. Four records were obtained by counting the chewing strokes number until the first swallow, the chewing strokes number until the mouth of patient became free of food, time (in seconds) till the first swallow, and time (in seconds) till the mouth of patient became free of food. The patient chewed one piece of each food five times, and the mean of the five recordings was considered the masticatory efficiency parameter for that patient ${ }^{(9)}$. Masticatory efficiency was measured again after one month. After one week washing period, patients then received the second denture with nano composite teeth. The masticatory efficiency was measured after a one-week adaptation period. It was measured again after one month.

\section{Laboratory study:}

\section{A-Wear}

Thirty specimens were constructed and divided into two groups. Group I: Fifteen specimens of IPN cross-linked acrylic teeth and Group II: Fifteen specimens of nano composite teeth.

\section{Wear resistance test}

The 2-body wear testing was performed using the ROBOTA dual-axis chewing simulator integrated with the servo-motor thermo-cyclic protocol (Model ACH-09075DC-T, AD-TECH Technology Co., LTD., Germany). The device allows simultaneous vertical and horizontal movements simulation in the thermodynamic condition. It has four chambers; each chamber has an upper compartment with a metal receptacle as a specimen holder and a lower compartment in which an antagonist of 600 grit sandpaper was used. Specimens were tested with a revolution of 37,500 cycles and an applied weight of 700 grams which is about $7 \mathrm{~N}$ of chewing force. The specimens were then removed, cleaned with running water then cleaned for 2 minutes in an ultrasonic cleaner thus any abraded particles would be removed from the specimens 'surface prior to measurement.

\section{Wear measurements}

The specimens 'height loss was evaluated using the digital micrometer (Mitutoyo Digimatic Caliper 25SB, Mitutoyo Corporation, Japan) where the amount of vertical loss was calculated from the difference between the readings of the specimens before and after wear simulation. Weight loss was evaluated by weighing the specimens to show the difference in their weight before and after wear test using the electronic analytical balance (Sartorius, Biopharmaceutical and Laboratories, Germany) which had a fully automated calibration technology and a micro weighing scale with an accuracy of 0.0001 gram. 
For a better reflection of the teeth surfaces and quantitative analysis of the wear areas, USB Digital Microscope with a built-in camera which is connected to an IBM compatible personal computer was used to photograph the wear of both buccal and lingual cusps with a fixed magnification of 120 xs. Subsequently, 3D images of the specimens "surface profile were created by a digital image analysis system. The unworn surface acted as a reference and the worn surface 3-dimensional geometry was generated.

\section{B- Micro tensile bond strength}

Total twelve first molar teeth were chosen and divided into two groups. Group I: six IPN Crosslinked acrylic teeth and Group II: Six nano composite teeth. The specimens were constructed by making twelve blocks of pink wax; each block with the denture tooth attached to it. The specimens were then invested using dental stone (Acrostone.Egypt) into a dental flask. After wax elimination, Heat polymerizable acrylic resin (Acrostone. Egypt) was prepared following the manufacturer's instructions and applied to the teeth within the space left. The resin was polymerized by a short cycle of hot water path at $74^{\circ} \mathrm{C}$ for 1.5 hour then water bath temperature was brought to $100^{\circ} \mathrm{C}$ for 1 hour. After the polymerization and cooling of the flask, the completed specimens were then deflasked.

The processed specimens were finished, polished, and then introduced to a diamond saw cutting machine (Isomet 4000 micro saw Buehler USA) for beams production. A specially designed gripping attachment with (L) shape was used to hold the specimens firmly in place, parallel to sectioning direction, and then they were serially sectioned using a diamond-coated disc of $0.3 \mathrm{~mm}$ thickness under copious coolant firstly in buccolingual direction, then in mesiodistal direction after being rotated $90^{\circ}$ clockwise.(Fig.1)

Each tooth produced ten beam specimens (adhesive area $1 \pm \mathrm{mm}^{2}$, length $8 \pm \mathrm{mm}$ ). The resultant beams were thermo cycled using thermo cycling device (THE-1100 SD Mechatronics thermocycler, Germany) between $5^{\circ} \mathrm{C}$ (cold water path) and $55^{\circ} \mathrm{C}$ (hot water path) 30 second for each temperature with a total 60-second for each cycle followed by 10 seconds rest before application of the next cycle. Approximately 5000 cycles which equal 6 months of intraoral aging were applied.

\section{Micro-tensile bond strength ( $\mu$ TBS) test}

Beam specimens were tested by introducing them to the Universal Testing Machine (Instron, 3345 model, England) which is controlled digitally and with software for test control and information acquisition (Bluehill version 3.3). Each beam was fixed to a metallic holding plate using cyanoacrylate based glue. Tensile load (500 N) was applied at the ends of the beam specimens with a crosshead speed of $0.5 \mathrm{~nm} / \mathrm{min}$ perpendicular to the tooth-denture

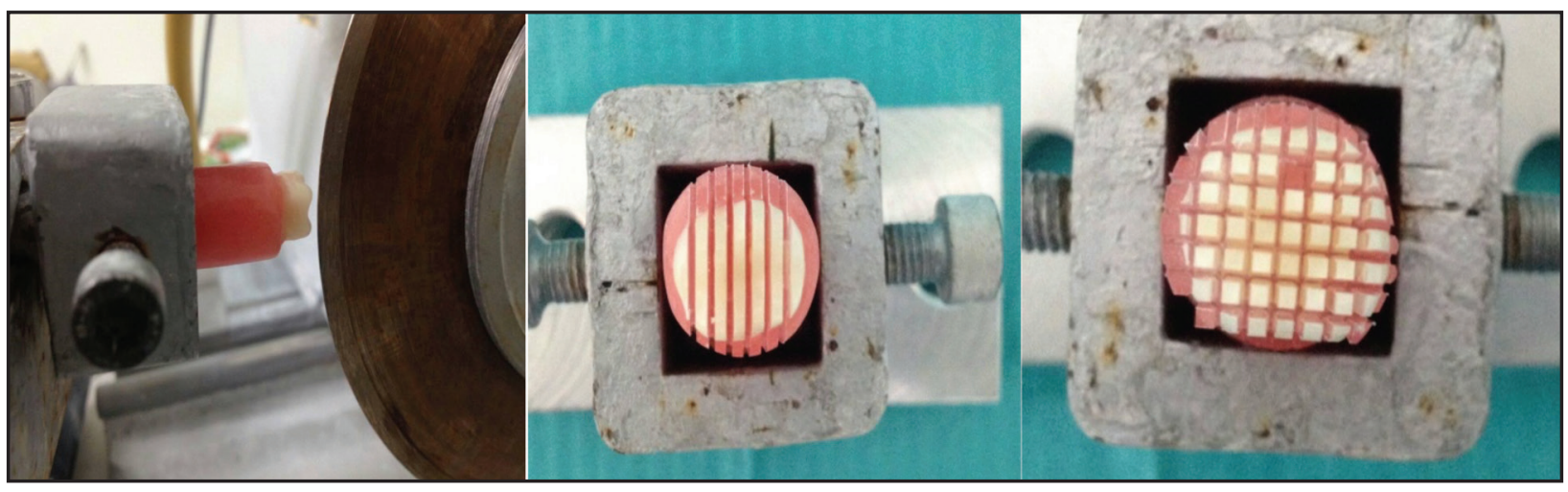

Figure (1) Sectioning of a specimen into beams using a diamond saw cutting machine (Isomet 4000) 
base interface until debonding of the specimens. Micro tensile bonding strength was evaluated in Mega Pascal (MPa). Specimen fragments were then carefully removed from the metallic holding plate and stored in their corresponding labeled plastic cones until the examination of failure mood.

\section{Statistical analysis}

The results were collected, tabulated, and statistically analyzed. Kolmogorov-Smirnov and ShapiroWilk tests were used to check the normality of the quantitative data which were found to be normally distributed so the mean and standard deviation (SD) were presented. Intergroup comparisons were analyzed utilizing paired t-test. The significance level was set at $\mathrm{p} \leq 0.05$ for all tests. Statistical analysis was done by SPSS (SPSS Inc., IBM Corporation,
NY, USA) Statistics Version 26 for Windows.

\section{RESULTS}

\section{Clinical study}

The mean values and standard deviations $(\mathrm{SD})$ for the masticatory efficiency test measured when chewing soft and hard food recorded for both experimental groups were in (Table 1).

The results of the current study showed that there were no statistically significant difference teeth between IPN cross-linked acrylic denture teeth and nano composite teeth in all of the masticatory efficiency parameters when patients were chewing soft food and hard food at the denture time of insertion and one month later.

Table (1) Comparison of masticatory efficiency parameters between IPN Cross linked acrylic denture teeth and nano composite teeth when chewing soft and hard food.(Paired t-test).

\begin{tabular}{|c|c|c|c|c|c|}
\hline \multirow{2}{*}{ Measurement } & \multirow{2}{*}{ Food } & \multirow{2}{*}{ Time } & \multicolumn{2}{|c|}{ Teeth $($ Mean \pm SD) } & \multirow{2}{*}{ p-value } \\
\hline & & & IPN Acrylic & Nano composite & \\
\hline \multirow{4}{*}{$\begin{array}{c}\text { Number of chewing } \\
\text { strokes till the first } \\
\text { swallow }\end{array}$} & \multirow{2}{*}{ Hard } & Baseline & $17.10 \pm 8.13$ & $16.92 \pm 7.15$ & $0.884 \mathrm{~ns}$ \\
\hline & & 1 month & $17.14 \pm 5.89$ & $15.86 \pm 6.29$ & $0.378 \mathrm{~ns}$ \\
\hline & \multirow{2}{*}{ Soft } & Baseline & $7.84 \pm 3.13$ & $7.60 \pm 0.99$ & $0.977 \mathrm{~ns}$ \\
\hline & & 1 month & $10.18 \pm 5.29$ & $7.58 \pm 1.97$ & $0.286 \mathrm{~ns}$ \\
\hline \multirow{4}{*}{$\begin{array}{l}\text { Number of chewing } \\
\text { strokes till mouth is free } \\
\text { of food }\end{array}$} & \multirow{2}{*}{ Hard } & Baseline & $25.32 \pm 9.42$ & $25.04 \pm 8.10$ & $0.865 \mathrm{~ns}$ \\
\hline & & 1 month & $26.68 \pm 9.44$ & $24.46 \pm 10.69$ & $0.302 \mathrm{~ns}$ \\
\hline & \multirow{2}{*}{ Soft } & Baseline & $12.38 \pm 3.39$ & $12.06 \pm 4.08$ & $0.337 \mathrm{~ns}$ \\
\hline & & 1 month & $15.12 \pm 7.24$ & $11.36 \pm 1.18$ & $0.249 \mathrm{~ns}$ \\
\hline \multirow{4}{*}{ Time till first swallow } & \multirow{2}{*}{ Hard } & Baseline & $14.32 \pm 6.37$ & $14.28 \pm 5.92$ & $0.145 \mathrm{~ns}$ \\
\hline & & 1 month & $15.54 \pm 5.54$ & $13.56 \pm 5.41$ & $0.973 \mathrm{~ns}$ \\
\hline & \multirow{2}{*}{ Soft } & Baseline & $7.70 \pm 1.08$ & $6.88 \pm 1.41$ & $0.216 \mathrm{~ns}$ \\
\hline & & 1 month & $9.18 \pm 3.41$ & $6.74 \pm 2.65$ & $0.089 \mathrm{~ns}$ \\
\hline \multirow{4}{*}{$\begin{array}{l}\text { Time till mouth is free } \\
\text { of food }\end{array}$} & \multirow{2}{*}{ Hard } & Baseline & $22.78 \pm 9.56$ & $22.32 \pm 8.07$ & $0.107 \mathrm{~ns}$ \\
\hline & & 1 month & $25.54 \pm 8.85$ & $22.30 \pm 9.23$ & $0.773 \mathrm{~ns}$ \\
\hline & \multirow{2}{*}{ Soft } & Baseline & $12.82 \pm 1.92$ & $12.10 \pm 2.66$ & $0.389 \mathrm{~ns}$ \\
\hline & & 1 month & $18.10 \pm 12.23$ & $11.88 \pm 3.76$ & $0.108 \mathrm{~ns}$ \\
\hline
\end{tabular}

Significance level $p^{*} \leq 0.05, S D=$ standard deviation. 


\section{Laboratory study}

\section{A-wear resistance:}

\section{Height results:}

The mean values and standard deviations (SD) for wear test measured by height loss $(\mathrm{mm})$ recorded for both experimental groups after 37,500mastication simulation cycles were summarized in (Table2).

IPN cross-linked acrylic teeth group had a value $(0.28 \pm 0.15)$, nano composite teeth group had a value $(0.20 \pm 0.17)$, and the difference was non-significant $(\mathrm{p} \leq 0.272)$.

\section{Weight results}

The mean values and standard deviations (SD) for wear test measured by weight loss (gram) recorded for both experimental groups after 37,500 mastication simulation cycles were summarized in (Table2).

IPN cross-linked acrylic teeth group had a value (7.30 \pm 1.71$)$, nano composite teeth group had a value (7.25 \pm 1.85$)$,and the difference was not significant $(\mathrm{p} \leq 0.949)$.

\section{Surface roughness:}

Microscopic images of IPN cross- linked acrylic denture teeth and nano-composite teeth were examined at 120X magnification, and represented in (Fig.2)

IPN cross-linked acrylic teeth had a value $(0.020 \pm 0.017)$, nano composite teeth group had a value $(0.016 \pm 0.018)$, and the difference was not significant $(\mathrm{p} \leq 0.775)$. (Table2)

\section{B-Micro tensile bond strength:}

The mean values and standard deviation (SD) values of micro tensile bond strength (Mpa) were summarized in (Table3).

IPN Cross-linked acrylic teeth group had a value (22.27 \pm 7.04$)$, nano composite teeth group had a value $(25.64 \pm 7.80)$, and the difference was nonsignificant $(\mathrm{p} \leq 0.102)$.

Table (2) Comparison of wear resistance parameters between IPN Cross linked acrylic teeth and nano composite teeth. (Paired t-test).

\begin{tabular}{cccc}
\hline \multirow{2}{*}{ Wear parameter } & \multicolumn{2}{c}{ Teeth (Mean \pm SD) } & \\
\cline { 2 - 3 } & IPN Acrylic & $\begin{array}{c}\text { Nano } \\
\text { composite }\end{array}$ & \\
\hline Weight loss (mg) & $7.30 \pm 1.71$ & $7.25 \pm 1.85$ & $0.949 \mathrm{~ns}$ \\
\hline Height loss (mm) & $0.28 \pm 0.15$ & $0.20 \pm 0.17$ & $0.272 \mathrm{~ns}$ \\
\hline $\begin{array}{c}\text { Surface } \\
\text { roughness }(\boldsymbol{\mu m})\end{array}$ & $0.020 \pm 0.017$ & $0.016 \pm 0.018$ & $0.775 \mathrm{~ns}$ \\
\hline Significance level $p^{*} \leq 0.05, S D=$ standard deviation.
\end{tabular}

Table (3) Comparison of microtensile bonding strength between IPN cross linked acrylic denture teeth and nano composite teeth. (Paired $t$-test).

\begin{tabular}{ccc}
\hline \multicolumn{2}{c}{ Teeth $($ Mean \pm SD) } & p-value \\
\cline { 1 - 1 } IPN Acrylic & Nano composite & \\
\cline { 1 - 2 } $22.27 \pm 7.04$ & $25.64 \pm 7.80$ & $0.102 \mathrm{~ns}$ \\
\hline
\end{tabular}

Significance level $p^{*} \leq 0.05, S D=$ standard deviation.

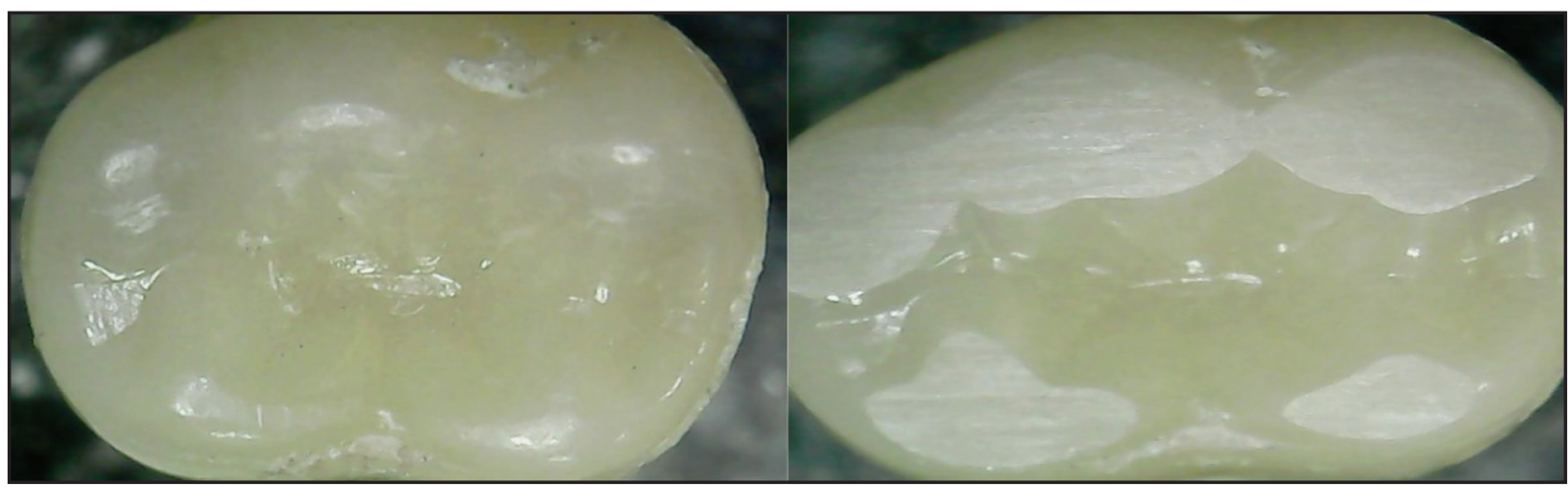

Figure (2) Photomicrograph of nanocomposite teeth; before wear (a), after wear (b) 


\section{DISCUSSION}

This study was designed as a prospective comparative clinical and laboratory trials to compare between two different artificial denture teeth materials (IPN cross-linked acrylic denture teeth and nano composite denture teeth) regarding their effect on the masticatory efficiency of complete dentures. Moreover, their wear resistance and micro tensile bond strength to denture base were evaluated.

In this clinical study, two sets of complete dentures with heat-cured acrylic resin base were constructed for each patient. One with IPN crosslinked acrylic teeth and the other with nano composite teeth. Patients with ages ranged from 5560 years were selected to avoid all factors which may affect the muscle tone and hence the resultant masticatory efficiency including various systemic diseases, neuromuscular disorders, muscle and mucosa atrophy, and excessive bone loss ${ }^{(10)}$.

The selected patients had a residual ridge with adequate healthy firm mucosa due to their important role in denture adaptation, stability, stress distribution, and hence masticatory efficiency. Patients with TMJ disorders and Parafunctional habits as bruxism or clenching were excluded to avoid the effect of abnormal/excessive stresses on the dentures ${ }^{(11)}$.

Natural test foods including banana as an example of soft food and carrot as an example of hard food were selected because of their reliable natural taste and suitability for complete denture wearers who could easily crush and comminute them. Both were cut into small and symmetrical pieces to eliminate the influence of different food sizes on masticatory efficiency $^{(11)}$.

The chewing strokes number and chewing times of a test food were compared for each patient. This technique was preferred by many authors as it is practical, applicable for all food types, and allows patients to chew and swallow normally. Moreover, it had a valid measure of masticatory efficiency ${ }^{(12)}$.

The results of this study approved that there is no statistically significant difference in all of the masticatory efficiency parameters when patients were chewing soft and hard food.

The results of this study can be explained by the theory of wear which is wear of denture teeth is directly related to masticatory efficiency as wear resistance enhances the denture teeth ability to maintain a stable occlusal relationship that produces better chewing and masticatory performance. Since there is no significant difference in wear resistance between nano composite and cross-linked acrylic teeth, thus there is a non-significant difference in masticatory efficiency between both types ${ }^{(13)}$.

Some authors reported that the concept of occlusion and anatomy of teeth either anatomical, semi anatomical ,or non-anatomical are the most important factors determining cutting efficiency, and therefore masticatory efficiency of denture teeth rather than the type of material used ${ }^{(14)}$.

In this study, the wear amount that happened under the same laboratory conditions between nano composite and IPN cross-linked acrylic teeth materials was compared by in vitro two-body wear technique using ROBOTA chewing simulator . Artificial denture teeth wear resistance can be tested in vitro by two- or three-body testing techniques. In this study, the two-body wear method was selected because it provides direct contact between the specimen and the antagonist simulating the situation in complete denture with bilaterally balanced occlusion. This contact does not occur significantly between maxillary and mandibular denture during food mastication, it happens normally in case of swallowing and Parafunctional habits leading to denture teeth wear. In contrast to the threebody testing method which usually measures the characteristics of wear, but its results may be influenced by several factors including the material of the used antagonist, abrasiveness and $\mathrm{pH}$ of the intermediate material $^{(8)}$.

First molars were only selected in each group to standardize and compare the samples .Moreover; chewing process mainly depends on posterior teeth 
and more load is applied to them thus they wear faster as compared to anterior teeth ${ }^{(15)}$.

In this study, $0.7 \mathrm{~kg} / \mathrm{mm}^{2}$ pressure was used for the wear simulation which is higher than the amount of pressure reported in the literature for complete denture occlusion $(0.4 \mathrm{~kg} / \mathrm{mm} 2)$. This higher pressure level was selected for simulation of the worstcase scenario that can occur as in a case of high occlusal contact, or improper balance of complete denture occlusion leading to increased pressure and wear in isolated areas ${ }^{(8)}$. Wear simulation with $37,500 \mathrm{cy}-$ cles was applied to simulate three months of clinical function according to previous studies ${ }^{(16,17)}$.

The results of this study showed a statistically non-significant difference in wear resistance between nano composite and IPN cross-linked acrylic denture teeth in agreement with previous studies $^{(18,19)}$. An explanation is that nano filler particles were added to denture teeth to improve their wear resistance due to the smaller size of the filler particle and decreased inter particle space among them; however, it was reported that these fillers have tendency for agglomeration forming clusters in the micrometer range. Moreover, they could be detached from the denture teeth surface during function resulting in excessive wear ${ }^{(20)}$.

The results of this study disagreed with other studies ${ }^{(21,22)}$ that measured the wear resistance in three different denture teeth $\mathrm{t}$ : Feldspathic ceramic, nano composite teeth, and acrylic teeth. Nano composite teeth were reported to be more suitable for complete and partial dentures due to their good wear resistance ${ }^{(22)}$. These conflicting data may be due to the difference in testing methods, specimen preparation techniques, and variation of denture tooth brands with the difference in their chemical compositions. The bond strength between two types of artificial denture IPN cross-linked acrylic teeth, nanocomposite denture teeth and heat cured acrylic resin denture base was studied by micro tensile bond strength test ( $\mu \mathrm{TBS})$. Bond strength can be evaluated by a variety of testing methods including shear, micro shear, and micro tensile tests. In this study, micro tensile bond strength ( $\mu$ TBS) was chosen as it permits the alignment of different samples in a proper way resulting in a stress pattern with a homogeneous distribution; also, it facilitates the longitudinal sectioning of the samples and provides better economic sample use ${ }^{(23)}$.

Thermo- cycling was used as an in-vitro environment to generate thermal changes similar to the oral cavity simulating the normal changes in temperature that human can withstand .The concept of thermocycling is that periodic contraction and swelling create stress inside the materials which deteriorates the bond between denture bases and teeth. Moreover; it gives rise to hydration of the samples, so the material imbibes water which diffuses directly into the bond site, squashes in the voids at the interface leading to stresses originated at the tooth- denture base interface and hence a deleterious effect on the bonding ${ }^{(24,25)}$.

Nanocomposite denture teeth showed statistically non-significant microtensile bond strength as compared to cross-linked acrylic teeth .This result agrees with a previous study ${ }^{(26)}$ which show that nanocomposite denture teeth comprise four individual layers. Composite material forms the dentin core and facial incisal layers so it provides superior esthetics. PMMA material forms the back incisal and cervical layers to give effective and stress-free bond with denture bases. Since the ridge lap portions of the two tested denture teeth were composed of acrylic resin, This might explain the non-significant difference in micro tensile bonding strength between the two groups ${ }^{(27)}$. In contrast to these findings, another study reported that cross-linked acrylic artificial teeth showed significantly higher bond strength as compared to nanocomposite teeth ${ }^{(28)}$. An explanation of these contrasting results is that the experimental tests are influenced by differences in the specimens size and shape, measuring devices, the amount of load used during the test, denture bases type, and method of polymerization. 


\section{CONCLUSION}

Within the limitations of the present study, Nanocomposite denture teeth exhibited a statistically non-significant difference in masticatory efficiency, wear resistance ,and microtensile bonding strength to heat cured acrylic resin denture base as compared to IPN cross-linked acrylic teeth.

\section{CONFLICT OF INTEREST}

None declared.

\section{FUNDING}

No funding was received for this study.

\section{REFERENCES}

1. Lee DJ, Saponaro PC. Management of Edentulous Patients. Dent Clin North Am. 2019;63:249-61

2. Mary KM, Cherian Evaluation of oral stereo gnosis, masticatory efficiency, and salivary flow rate in complete denture wearers. J Indian Prosthodont Soc 2020;20:290-6

3. Uehara PN, Iegami CM, Tamaki R, Ballester RY, de Souza RM, Laganá DC. Analysis of behavior of the wear coefficient in different layers of acrylic resin teeth. J Prosthet Dent 2019:121:967.

4. Pande N, Zarekar S, Jaiswal P.Evaluation of shear bond strength of acrylic resin teeth to heat-polymerized denture base resin before and after thermo cycling: An in vitro study. Indian J Multidiscip Dent 2018;8:25-32

5. MoffittAR, Woody RD, Parel SM, Miller BH. Failure modes with point loading of three commercially available denture teeth. J Prosthodont. 2008; 17:432-8.

6. McCabe JF, Walls A. Applied dental materials. $9^{\text {th }}$ ed. Oxford: Wiley Blackwell; 2009; 133-52.

7. Helal MA, Yang B, Saad E, Abas M, Al-kholy MR, Imam AY,et al.,Effect of $\mathrm{SiO}_{2}$ and $\mathrm{Al}_{2} \mathrm{O}_{3}$ nanoparticles on wear resistance of PMMA acrylic denture teeth. Braz Den Sci. 2020;23:12

8. Munshi N ,Rosenblum M, Jiang S, Flinton R. In vitro wear resistance of nano-hybrid composite denture teeth. J Prosthodont. 2017;26:224-9.

9. Mousa MA, Patil S, Lynch E. Masticatory efficiency and muscular activity in removable partial dental prostheses with different cusp angles.J Prosthet Dent. 2017;117:55-60.
10. Palinkas M,Nassar MS,Cecilio FA, Siéssere S, Semprini M, Machado-de-Sousa JP, et al., Age and gender influence on maximal bite force and masticatory muscles thickness. Arch Oral Biol. 2010;55:797-802.

11. Abd El Aziz O, Saba EKA, Mesallati SA. Masticatory efficiency of complete dentures constructed by different denture base materials. Int J Sci and Research. 2016; 5:1292-9.

12. Baraka YA. The masticatory efficiency of complete denture wearers with occlusal plane orientation using Camper's line with different levels of the tragus. E D J. 2017; 63:1923-30

13. Suwannaroop P, Chaijareenont P, Koottathape N, Takahashi $\mathrm{H}$, Arksornnukit M. In vitro wear resistance, hardness and elastic modulus of artificial denture teeth. Dent Mater J. 2011;30:461-8.

14. Hashimoto $\mathrm{Y}$, Sugimoto $\mathrm{K}$, Tanaka $\mathrm{Y}$, Sugimoto $\mathrm{H}$, Minagi S. Short-Term Crossover Study on the Effect of Orthogonalized Deep-Grooved Posterior Artificial Teeth on the Masticatory Efficiency of Complete Denture Wearers. Open DentJ .2018;12:255-64.

15. Reis KR, Bonfante G, Pegoraro LF, Conti PC, Oliveira $\mathrm{PC}$, Kaizer OB. In vitro wear resistance of three types of polymethyl methacrylate denture teeth. J Appl Oral Sci. 2008;16:176-80.

16. Abdalla MM, Masoud MA.Wear resistance of Nano silica modified acrylic denture teeth and Nano filled composite denture teeth. E D J. 2018; 64:3651-9.

17. Mello PC, Coppedê AR, Macedo AP, de Mattos Mda G, Rodrigues RC, Ribeiro RF. Abrasion wear resistance of different artificial teeth opposed to metal and composite antagonists. J Appl Oral Sci. 2009; 17:451-6.

18. Suzuki S. In vitro wear of nano-composite denture teeth. J Prosthodont. 2004; 13:238-43.

19. Abbas M, Sakr H. Wear performance of Nano-composite artificial denture teeth .EDJ. 2017; 63:2535-44.

20. Stober T,Henninger M, Schmitter M, Pritsch M, Rammelsberg P. Three-body wear of resin denture teeth with and without nanofillers. J Prosthet Dent. 2010; 103:108-17.

21. Ilangkumaran R, Srinivasan J, Baburajan K, Balaji N. Two Body Wear of Newly Introduced Nanocomposite Teeth and Cross Linked Four Layered Acrylic Teeth: a Comparitive In Vitro Study. J Indian Prosthodont Soc. 2014;14:126-31.

22. Ghazal M, Hedderich J, Kern M. Wear of feldspathic ceramic, nano-filled composite resin and acrylic resin artificial teeth when opposed to different antagonists. EurJOralSci. 2008;116:585-92. 
23. Coppini EK, Prieto LT, Pierote JJ, Pimenta CT. Influence of enamel acid-etching on mechanical properties and nanoleakage of resin composite after aging. Braz J. oral sci.2017; 16:17059.

24. Aljudy HJ, Hussein AN, Safi IN. Evaluation of Bond Strength of Surface Conditioned Artificial Teeth with Modified and Valplast Denture Bases With Aging. Iraqi Dent J. 2015; 37:3797-106.

25. Abd El Hameed H. An-invitro comparison of Thermocycling Effect on Micro- hardness and Micro-tensil bond strength of Nano composite denture teeth. E D J. 2019; 65:1495-01
26. Chittaranjan B, Taruna M, Sudheer N, Patil NS. Evaluation of shear bond strength of three different types of artificial teeth to heat cure denture base resin: an in vitro study. Indian J Dent Res. 2013; 24:321-5.

27. Mosharraf R, Abed-Haghighi M. A comparison of acrylic and multilithic teeth bond strengths to acrylic denture base material. J Contemp Dent Pract. 2009;10: 17-24.

28. Gharebagh TG, Hamedirad F, Miruzadeh K. Comparison of Bond Strength of Acrylic, Composite, and Nanocomposite Artificial Teeth to Heat-Cure Acrylic Denture Base Resin. Front Dent. 2019;16:166-72. 